\title{
Otrágico nas sociologias de Georg Simmel e Max Weber
}

\section{Alyson Thiago Fernandes Freire*}

\section{Resumo}

Este artigo se propõe, de uma maneira não exaustiva, a apresentar e discutir em quais componentes do pensamento sociológico de Georg Simmel e Max Weber podemos identificar a atuação de uma sensibilidade trágica na abordagem dos processos conformadores da cultura moderna. No primeiro, identificamos o "ponto de vista trágico" enquanto ambivalência e uma pressuposição de autocontradição fundamental inscrita nos processos e fenômenos constitutivos do estilo de vida moderno. No segundo, esforçamo-nos em exprimir como o trágico emerge, de maneira surpreendente, irônica e indesejada, das consequências não previstas e não intencionais da ação dos agentes.

Palavras-chave: Trágico, Simmel, Weber, Sociologia da modernidade.

\section{The tragedy in the sociologies of Georg Simmel and Max Weber}

\section{Abstract}

This article discusses, although not exhaustively, the components of sociological thought of Georg Simmel and Max Weber that allow to identify the performance of a tragic sensitivity in the analysis of the processes that constitute the modern culture. In the first author, we identify the "tragic point of view" as ambivalence and the assumption of a fundamental self-contradiction embedded in the processes and phenomena that constitute the modern life style. In the second author, we try to reveal how the tragedy arises, in a surprising, ironic and undesirable way, from the unpredictable and unintentional consequences of the actions of agents.

Keywords: Tragic, Simmel, Weber, Sociology of modernity.

*Instituto Federal de Educação, Ciência e Tecnologia do Rio Grande do Norte. Macau, RN, Brasil 


\section{Introdução}

Mas não é trágico que o homem seja levado pela divindade a experimentar o terrível, e sim que o terrível aconteça por meio do fazer humano.

(Szondi, 2004, p. 89)

As épocas em que predominam crenças comparativamente estáveis não produzem tragédias de nenhuma intensidade, [...] O seu cenário histórico mais usual é o período que precede à substancial derrocada e transformação de uma importante cultura.

(Williams, 2002, p. 79)

o estudar o mundo social e as relações humanas, os sociólogos n não são apenas informados por teorias, conceitos especializados e técnicas de investigação. Suas pesquisas não são apenas animadas pelas regras, procedimentos e valores científicos, mas também por escolhas epistemológicas, ontológicas e metafísicas, tácitas ou não. Essas pressuposições gerais inarticuladas, cujo caráter transcende o domínio estrito da prática científica, possuem, no entanto, um papel na orientação do conhecimento sociológico produzido, isto é, estão intimamente conectadas à interpretação feita pelos sociólogos dos fenômenos sociais que estudam.

A produção do conhecimento sociológico não é esvaziada de a priori culturais, ideológicos, filosóficos e metafísicos. A sociologia, e suas generalizações teóricas e conhecimento empírico, existem, também, atreladas a imaginários sociais, em referências aos quais os seus esquemas analíticos e proposições ganham significado e orientação, segundo determinadas concepções tácitas sobre a natureza da ação humana, da ordem social, da história, e, inclusive, sobre o próprio papel da sociologia na sociedade (Alexander, 1987). 
A tese acima pode ser evidenciada por intermédio das raízes culturais que irrigam a emergência e o desenvolvimento da sociologia no mundo moderno. A sociologia nasce no interior de um complexo sociocultural no qual, grosso modo, dois imaginários sociais (Taylor, 1996) se enfrentam - com intensas repercussões nas manifestações artísticas, filosóficas e científicas da época - na luta pela definição e orientação do mundo moderno e da cultura europeia do século XIX. A sociologia nascente debate-se entre uma concepção iluminista do moderno e uma concepção romântica do moderno (Gouldner, 1973).

Derivam, certamente, dessa tensão fundante e do seu inescapável papel na estruturação da cultura e da identidade modernas, a oscilação e a controvérsia em ora conceber a sociologia como como herdeira do Iluminismo e do liberalismo Ilustrado (Aron, 2008; Seidman, 1983), ora entendê-la como o rebento rebelde contra a llustração e a mentalidade clássica, ou seja, como fruto do Romantismo, do pensamento conservador ou do espírito reformista dos oitocentos (Nisbet, 1969; Gouldner, 1973). As tensões e as concepções simbólicas que marcaram e definiram os movimentos culturais e filosóficos da cena intelectual europeia nos séculos XVIII e XIX deixaram marcas profundas na ciência da sociedade. Elas são parte essencial das raízes da sociologia enquanto forma de conhecimento, integram o corpo de tradições de ideias e crenças que formaram e estruturam ainda hoje a imaginação conceitual da sociologia e suas grandes linhas divisoras.

O corpus de ideias e crenças compartilhadas que distinguem os imaginários sociais iluminista e romântico constitui dimensões inarticuladas do campo discursivo sociológico. São "estruturas profundas", como diria Alvin Gouldner (1973), às quais ainda não se tem dedicado a devida atenção, no que diz respeito ao seu papel na configuração e alimentação dos esquemas cognitivos e metodológicos e das premissas normativas das diferentes formas de praticar sociologia e de pensar sociologicamente (Gouldner, 1973). Por mais importantes e fundantes que possam ser como "estruturas profundas" da sociologia, o classicismo racionalista e o romantismo não esgotam as dimensões latentes desta ciência. Existem outras "estruturas profundas" 
inarticuladas, oriundas de tradições culturais e estilos de pensamento cujas fontes e repertórios de ideias e crenças não necessariamente coincidem ou derivam das destacadas por Gouldner em seu clássico artigo. Por exemplo, a visão trágica da existência que acompanha a cultura do Ocidente, desde o teatro grego, até as filosofias neorromânticas da cultura, passando pela dramaturgia renascentista e clássica.

Neste artigo, gostaria, então, de explorar essa fonte expressiva de pensamento particular que é o trágico, ou a visão trágica da existência humana. Para isso, tomarei como exemplo os esquemas interpretativos das sociologias de Georg Simmel e Max Weber, com o objetivo de discutir como estes autores recorrem ao que chamaremos de "ponto de vista trágico" como uma perspectiva de abordagem e de entendimento dos processos históricos constitutivos da cultura e da sociedade modernas. Porém, ressalto de saída, sem a ambição de esgotar todas as possibilidades e ocorrências em que se poderiam verificar as conexões dos conceitos e das análises desses autores com a sensibilidade trágica ou mesmo o pensamento social de autores.

Não se trata, portanto, de examinar as raízes culturais ${ }^{1}$ da visão trágica sobre a realidade social ou a partir de que contexto estes autores a abraçaram como perspectiva de conhecimento, mas sim de localizar, em seus esquemas de análise, como este ponto de vista opera em sua interpretação e no diagnóstico crítico do mundo moderno.

\section{A sociologia alemã: um olhar singular}

Wolf Lepenies, em um primoroso estudo sobre as cenas intelectuais de Alemanha, França e Inglaterra da passagem do século XIX para o XX, avança sobre a hipótese que Alvin Gouldner esboçara anos antes, sobre os embates entre o romantismo e o classicismo nas definições das diferentes

\footnotetext{
${ }^{1}$ A reflexão sistemática sobre a arte grega e o significado da tragédia para a constituição da arte, cultura e identidade alemãs faz parte do efervescente cenário cultural e filosófico germânico desde meados do século XVIII, com nomes como Winckelmann, Goethe, Schiller, Hölderlin, Nietzsche, entre outros. Para maiores detalhes, ver Machado (2006).
} 
orientações teórico-metodológicas da sociologia. Lepenies, por seu turno, situa os pais fundadores da sociologia no seio da crise da modernidade, enfatizando como sociólogos e artistas, nos diferentes contextos nacionais, responderam ao conflito entre racionalismo e romantismo, ora definindo distâncias e antagonismos, ora abraçando afinidades e conexões entre seus ofícios, ambições e preocupações (Lepenies, 1996).

De acordo com Lepenies, o desenvolvimento da sociologia alemã orientou-se por um diálogo mais íntimo e profícuo com o mundo das vanguardas estéticas e filosóficas em geral do que as demais sociologias em outras paragens nacionais. Enquanto, na França, a sociologia desenvolveuse sob o arco da influência das ciências naturais e da mentalidade clássica, na Alemanha, coube à poesia, ao teatro e à música este papel formativo, de orientação muito mais subjetivista e hermenêutica do que a orientação, digamos, mais positivista e cientificista dos franceses. Mais do que homens de letras e cientistas, o clima intelectual alemão em que nasce e cresce a sociologia era agitado pelas ideias de poetas e pensadores que se contrapunham, desde o fim do século XVIII, com o Sturm und Drang, ao formalismo racionalista do mundo cultural francês e sua euforia pela ciência positiva (Lepenies, 1996, p. 204).

Na Alemanha dos séculos XVIII e XIX, na esteira da querela dos antigos e modernos e das repercussões da filosofia de Kant, o ambiente intelectual alemão voltou-se particularmente para uma discussão intensa acerca do valor e do significado da tragédia grega. $\mathrm{O}$ mote desse debate girou em torno da questão da comparação e avaliação entre as tragédias antigas e modernas, sobretudo em termos do seu sentido histórico para compreender tanto as continuidades e descontinuidades do mundo moderno em relação à antiguidade clássica, como seus problemas éticos e políticos (Billings, 2014).

Escritores, como Herder e Hölderlin, e pensadores pós-kantianos, como Schiller, Schelling, os irmãos Schlegel, Hegel, Schopenhauer e Nietzsche são alguns dos nomes que se engajaram numa reflexão filosófica sobre a tragédia grega e moderna. Esses autores tomaram o estudo e exame 
crítico da tragédia como um modelo de compreensão e crítica de seu próprio tempo. O trágico é concebido como uma chave interpretativa para as questões do sentido da história, da liberdade humana, da singularidade da experiência estética e teleológica, das aporias da relação sujeito e objeto, inteligível e sensível, o papel do gênio e do sublime na cultura, além de operar como contraponto crítico à metafísica platônica e judaico-cristã (Billings, 2014).

Não nos interessa aqui entrar nas nuanças desse contexto e suas obras ou nos detalhes das diferenças entre "tragédia" e "trágico", entre a tragédia como gênero literário dos antigos e o trágico como filosofia dos modernos, entre arte trágica e teoria do trágico (Szondi, 2004)² . Basta-nos, segundo nossos propósitos, acentuar a presença desse contexto anterior de discussões como parte integrante do ambiente intelectual em que Simmel e Weber se formaram. A influência desse contexto intelectual pós-kantiano, suas discussões sobre a tragédia e o trágico, e o contato com as vanguardas artísticas são, sem dúvida, fontes das quais Simmel e Weber absorveram um ponto de vista trágico sobre o desenvolvimento histórico e as ações humanas.

O confronto com o pensamento de Nietzsche - que, no final do século XIX e início do XX, era particularmente forte no ambiente cultural alemão, inclusive nos círculos dos cientistas sociais (Solms-Laubach, 2007) - ocupa, certamente, um lugar privilegiado nessa acomodação do ponto de vista trágico de nossos autores. Simmel, aliás, escreveu um estudo a propósito de Nietzsche, que incluía também Schopenhauer. Max Weber leu com grande interesse esse estudo (Simmel, 2011), embora não sem críticas à leitura simmeliana do filósofo de $A$ genealogia da moral. De todo modo, o perspectivismo e a visão agonística do mundo humano, ideias-força do pensamento trágico nietzschiano, constituem ingredientes relevantes das sociologias de Simmel e Weber, principalmente de suas epistemologias e diagnósticos críticos sobre o mundo moderno (Frisby, 2006).

2 Para maiores detalhes com respeito às distinções entre a forma literária da tragédia e as filosofias do trágico, ver Szondi (2004). 
A proximidade entre a intelligentsia acadêmica e as elites intelectuais e artísticas, na Alemanha da passagem do século XIX para o XX, não era apenas de ideias e inspiração intelectual. Ela afirmava-se como sociabilidade, círculos de amizade, debates e estudos, uma convivência de trocas intelectuais e afetivas entre artistas, intelectuais e estudiosos. Especialmente na Alemanha do fin du siècle, cientistas sociais e artistas compartilhavam e respiravam um mesmo clima intelectual e estado de ânimo, um mesmo pathos em relação ao presente. O famoso "Círculo Weber de Heidelberg", que reunia sociólogos, economistas, políticos, filósofos, escritores e poetas como Stefan George, Paul Ernst, Rainer Maria Rilke e Thomas Mann, é um exemplo vivo dessa profunda convivência entre intelectuais e artistas na cena intelectual alemã (Lepenies, 1996).

Esta convivência íntima entre cientistas sociais e o cenário cultural germânico mais amplo do século XIX e início do XX não passou imune ao tipo de olhar sociológico bastante peculiar que a tradição alemã lançaria sobre o mundo social. De Marx a Weber, passando por Simmel e Tönnies, a imaginação sociológica da tradição alemã é atravessada por várias das principais preocupações e pressuposições dos movimentos estéticos nascidos na esteira do Sturm und Drang e do Romantismo.

O viés crítico contra o mundo moderno industrial e o modo burguês de vida, apontados como os responsáveis por diversas consequências patológicas sobre a autoexpressão individual e as relações humanas, foi, com efeito, um dos legados que a sociologia alemã ${ }^{3}$ mais absorveu dessa mentalidade romântica reativa, que animava o clima cultural alemão dos novecentos.

Desse caldo cultural expressivista, do qual a ciência social alemã recebeu diversos impulsos para os seus principais traços e que the serviu

\footnotetext{
${ }^{3}$ Partindo de uma reflexão similar, e aprofundando os laços intelectuais existentes entre Romantismo e Ciências Sociais, o antropólogo Luiz Fernando Dias Duarte (2004) amplia o escopo dessas afinidades alargando-o para todo o universo das ciências humanas, não apenas da sociologia alemã, como destaco e me atenho aqui.
} 
como fonte de inspiração intelectual e epistemológica ${ }^{4}$ no que diz respeito ao seu olhar singular sobre o mundo e as condutas humanas, posso destacar ainda: a ênfase na historicidade; o peso da cultura na determinação do espírito de um povo, sociedade ou época; a importância da interpretação dos sentidos e significados interiores da vida e das condutas individuais; o papel e atuação de forças irracionais na configuração e no devir da vida; o ceticismo com relação à razão, à cientificização e ao progresso. Os conceitos sociológicos e as generalizações teóricas criadas por Tönnies, Simmel e Weber estão carregados, em muitos dos seus principais componentes, pelas imagens artísticas e as fórmulas de pensamento e de sensibilidade estéticas (Nisbet, 1969).

A sociologia alemã, portanto, exprime de maneira muito explícita como o conhecimento sociológico é nutrido por fontes e repertórios culturais que transcendem o microcosmo científico. Fontes e repertórios que provêm das filosofias, vanguardas artísticas, da religião luterana, entre tantas outras mais. Simmel e Weber são notórios exemplos de intelectuais alemães que souberam absorver as mais variadas tendências da cultura alemã: o romantismo, a lebensphilosophie, o neokantismo, o historicismo, o neoromantismo anticapitalista.

\section{O trágico como visão de mundo}

As expressões "tragédia" e "trágico" possuem sentidos diversos. Não são termos unívocos, independentes dos contextos culturais e situações sociais nos quais são acionados. Por exemplo, na vida corrente das sociedades modernas ou, sobretudo, nos espaços midiáticos, utiliza-se "tragédia" ou "trágico" para referir algum episódio ou evento real calamitoso, funesto, cujo desenlace foi terrivelmente chocante e fatal para os envolvidos.

${ }^{4}$ Não por acaso, portanto, que dois dos conceitos mais conhecidos de Max Weber, desencantamento do mundo e afinidade eletiva, foram extraídos das obras dos poetas e dramaturgos Friedrich von Schiller e Wolfgang von Goethe, respectivamente. A presença e a importância da arte em Simmel podem ser observadas pelas análises e ensaios que este autor dedicou a Goethe e ao pintor Rembrandt. 
No entanto, essas expressões e adjetivos estão ancorados numa tradição cultural e filosófica muito mais complexa e rica do que sugere o uso coloquial da vida cotidiana e do sensacionalismo midiático. Sua importância e papel na cultura e pensamento do ocidente podem ser avaliadas por sua trajetória histórica e cultural ao longo das épocas. De Sófocles (495 - 405 a.C.) a Racine (1639 - 1699) e de Aristóteles a Nietzsche, a tragédia e o trágico constituíram simultaneamente uma fonte inesgotável de criação artística e literária de diferentes dramaturgos e escritores e objeto de intensas reflexões teóricas, estéticas e filosóficas.

Como gênero literário, "tragédia" refere-se a um estilo dramático composto de textos e peças clássicas, basilares da arte e cultura ocidental, que percorre, não sem diferenças e ambiguidades relevantes, a Grécia Antiga de Ésquilo (525-456 a.C.), Sófocles e Eurípedes (480-406 a.C), a Renascença e as "tragédias modernas" de Shakespeare (1564-1616), Corneille (1606-1684) e Racine, até culminar nas reflexões nostálgicas e filosóficas da Alemanha Pré-Romântica de Schiller (1759-1805), Goethe (1759-1832), Hölderlin (1770-1843), entre outros (Machado, 2006).

Mais importante para o artigo é compreender o trágico como uma visão de mundo compartilhada que, seja no teatro grego, nas filosofias pré-socráticas e nas sistematizações teóricas dos românticos e dos filósofos idealistas pós-kantianos ou nos aforismos nietzscheanos, apresenta algumas pressuposições normativas e cosmológicas partilhadas, tais como a ideia de caos e de contingência do mundo, o agonismo da vida e a necessidade ética de enfrentamento do destino, a vulnerabilidade da liberdade e do conhecimento humano, o conflito entre valores e os imperativos morais de uma ética heroica aristocrática, entre outros (Lesky, 2006). É nesse sentido que trabalharemos o trágico como um estilo de pensamento que fornece uma perspectiva sobre a existência humana e alguns de seus problemas centrais.

O trágico diz respeito a uma "concepção de mundo como sede da aniquilação absoluta de forças e valores que necessariamente se contrapõem, inacessível a qualquer solução e inexplicável por nenhum sentido transcendente" (Lesky, 2006, p. 38). 
Como visão de mundo ou ontologia, o trágico designa um tipo peculiar de entendimento e sensibilidade acerca do lugar do ser humano e da ação humana face às inesgotáveis, imperscrutáveis e irremediáveis forças e poderes do universo e do destino, inclusive daquelas desencadeadas pelo finito engenho humano. Este entendimento e sensibilidade são traduzidos numa concepção da existência, segundo a qual esta última é regida e selada pela experiência do paradoxo e da tensão entre intenções e forças irreconciliáveis, em que a vida, o ser humano, a liberdade e o juízo humanos são expostos ao acaso, à contingência, ao inesperado.

É essa concepção do devir e do sentido do curso do mundo que pretendo localizar nas interpretações da configuração da cultura moderna elaboradas por Simmel e Weber. Meu propósito sobre o trágico consiste, com efeito, nesses conteúdos metafísicos e representações da existência, da condição humana e do curso do mundo que formam esta singular tradição cultural e estilo de pensamento, e não nos aspectos estéticos, históricos ou teóricos que vigoram e perpassam as formas artísticas e algumas filosofias da cultura ocidental.

O trágico é definido, sobretudo, pela experiência da tensão, do embate inelutável contra forças irrefreáveis, contra as quais encontrar uma solução simples, definitiva, harmônica não é uma alternativa. A visão trágica sobre o existir humano acolhe os contrários em sua plenitude e inevitabilidade; prazer e dor, alegria e sofrimento, vida e morte, acaso e destino, justiça e injustiça são forças imanentes do mundo e da condição humana neste mundo, das quais não se pode fugir em nome de ilusões reconfortantes. Acreditar que podemos controlar e aplacar essas forças, seja pela crença no poder de nossas capacidades e ações ou por acreditar em recompensas e interferências divinas no reestabelecimento da justiça e do bem verdadeiros, é ao mesmo tempo uma postura covarde, ingênua e inútil. Não é gratuito, portanto, que Hölderlin sustente categoricamente que "o significado da tragédia se deixa conceber mais facilmente no paradoxo" (Hölderlin, 1994, p. 63). 
Vejamos, então, como e onde este singular ponto de vista sobre a existência e a ação humanas, o "ponto de vista trágico", opera nos esquemas de análise das teorias sociológicas de Simmel e Weber, particularmente na interpretação destes autores acerca do desenvolvimento da cultura moderna. Partiremos do pressuposto segundo o qual, tanto Simmel quanto Weber, tomam a história e o processo de formação da cultura moderna como portadores e desencadeadores de paradoxos essenciais e distintivos. A nosso ver, o ponto de vista trágico repousa, precisamente, sobre este entendimento particular acerca da complexidade constitutiva da modernidade ocidental, isto é, sobre uma forma peculiar de abordar e compreender o desenvolvimento histórico e os processos sociais constitutivos da cultura moderna.

Para ambos sociólogos, a configuração da cultura e sociedade modernas, mas também os tipos psicológicos a estas afeiçoados são, por excelência, marcados por tensões surgidas ou acentuadas no decorrer do próprio processo de desenvolvimento histórico da modernidade. Esta é definida, sobretudo, pela experiência da ambivalência e do paradoxo, os quais não podem ser, em si mesmos, resolvidos e aplacados em definitivo por soluções éticas, cognitivas ou políticas finalistas. Eis aí precisamente outro dos traços mais marcantes do trágico, a saber: a não reconciliação, ou, conforme as palavras de Nietzsche "Todo o existente é justo e injusto e igualmente legítimo em ambos" (Nietzsche, 2006, p. 98).

\section{Simmel: o trágico como autocontradição e ambivalência}

Se quisermos examinar em que aspectos da teoria social de Georg Simmel (1858-1918) se manifesta um "ponto de vista" trágico, devemos procurá-los na maneira como este autor compreende os efeitos dos fenômenos estruturantes da cultura e sociabilidade modernas sobre a vida do espírito. Para Simmel, a modernidade é modelada por forças sociais e conteúdos contraditórios e ambivalentes entre si, engendrados, sobretudo, pela consolidação da economia monetária. 
$\mathrm{Na}$ análise das principais teses dos ensaios em que Simmel examina as tendências socio-históricas e os impulsos vitais que imprimem o selo batido da forma de vida moderna, encontraremos um princípio ontológico importante que orienta o seu entendimento sobre a natureza, a relação e os efeitos dos fenômenos sociais estudados pelo autor. Trata-se, a meu ver, de um princípio de autocontradição e autoantagonismo que seria inerente aos processos e forças da vida. É sobre ele que gostaríamos de sustentar o "ponto de vista trágico" simmeliano sobre a realidade social.

$\mathrm{Na}$ reflexão sociofilosófica simmeliana, vida e forma constituem oposições que existem, no entanto, inextricavelmente como interdependentes uma da outra. Como podemos notar, a autocontradição já se exprime, com efeito, nos pressupostos ontológicos de vida e devir de Simmel, pois a vida, sendo fluxo, sofre com a contradição de que somente pode se apresentar a partir daquilo que é o seu oposto, isto é, numa forma (Simmel, 2001). Nesse sentido, no seio dos processos vitais de conformação das formas sociais de vida coexistem opostos em patente tensão e embate. Tal ideia não nos parece de todo arbitrária, pois o próprio autor, numa assertiva sobre a trágica contradição da condição do mundo, afirmou que a existência é, "em última instância, uma autocontradição" (Simmel, 1986, p. 52).

A visão trágica enquanto autocontradição é um dos pilares, como veremos, de toda a crítica do mundo moderno em Simmel. Ela está presente na crítica do dinheiro, da divisão do trabalho e da contradição entre cultura objetiva e cultura subjetiva. Em Simmel, o trágico diz respeito a uma concepção metafísica acerca da vida humana e de seus processos significativos, que assinala como dado fundamental o vaticínio de que as forças criativas e destruidoras de um fenômeno vigem nele mesmo, são interiores, isto é, encontram-se em seu engendramento e desenvolvimento. O recurso a uma concepção do trágico como autocontradição é explicitado por Simmel na citação a seguir, em que o sociólogo berlinense explica por que se refere às ambivalências da época moderna a partir do conceito de "tragédia da cultura": 
[...] como destino trágico - em contraposição ao triste ou ao que destrói a partir de fora - entendemos o seguinte: que as forças aniquiladoras dirigidas contra uma essência brotam das camadas mais profundas desta mesma essência; que com a sua destruição se consuma um destino que já estava instalado nela mesma e que o desenvolvimento lógico constitui justamente a estrutura com a qual a essência construiu sua própria positividade (Simmel, 2005b, p. 104).

Em outras palavras, a reflexão sociofilosófica simmeliana assume como pressuposição básica da cultura, do devir histórico e do agir humano, a fórmula de uma "tragédia imanente", a qual se aloja e atravessa, por inteiro, a existência humana e o processo mesmo de engendramento das formas sociais de objetivação da vida. Podemos observar esse ímpeto no seu estudo sobre o significado histórico-cultural e psicológico da generalização das relações monetárias na modernidade, isto é, o dinheiro.

O advento e institucionalização da economia monetária constitui o fenômeno estrutural e cultural mais importante da modernidade para Simmel. Ele define a contradição mais fundamental da época moderna em comparação e oposição à época medieval. Os principais traços e dilemas da forma de vida moderna, a intelectualização e a aceleração do ritmo de vida e a prevalência da cultura objetiva sobre a cultura subjetiva podem ser delineados a partir do impacto e dos desdobramentos da consolidação da economia monetária na sociedade moderna (Simmel, 2005c).

O dinheiro, no mundo moderno, é o fenômeno ambíguo por natureza, capaz de realizar "inversões teleológicas" que o convertem, de um meio para fins individuais, em um fim supremo para os variados outros fins perseguidos pelos indivíduos. O dinheiro, observa Simmel em sua obra clássica, possui a estranha e inusitada força de unir os aparentemente opostos, como o avaro, que deseja e ama o dinheiro sobre todas as coisas para mantê-lo diante de si, o asceta, que o rejeita sobre todas as coisas como signo por excelência de contaminação dos valores elevados, e o pródigo, que deseja intensamente o dinheiro somente para se livrar dele e oferecê-lo a outrem (Simmel, 1977). 
O dinheiro constitui a ambiguidade profunda de ruptura no âmbito da cultura e da constituição do indivíduo moderno, pois, como já havia demonstrado Karl Marx, mais do que simplesmente um instrumento monetário e econômico de equivalências abstratas para as trocas materiais, o dinheiro é, antes, uma síntese de relações sociais complexas; a quantidade de trabalho humano abstrato nas mercadorias, no autor do Capital, e o processo de objetivação da cultura material e seu desprendimento cada vez maior da cultura subjetiva dos sujeitos, em Simmel. Para este último, a economia monetária "possibilitou a autonomia da personalidade e deu a ela maior liberdade de movimentos interna e externa incomensurável" (Simmel, 2005c, p. 23), pois provocou uma despersonalização das relações de trabalho, quer dizer, a personalidade ou a pessoa do empregado não está em negociação quanto à posse e ao usufruto pelo contratante. Apenas o seu tempo e sua força (trabalho objetivado) em troca de um salário. Com isso, o dinheiro desmantelou os constrangimentos orgânicos e comunais típicos do medievo e da propriedade feudal.

Por um lado, o dinheiro abriu as portas para um maior desenvolvimento e autodeterminação da individualidade, porquanto implodiu as barreiras das formas sociais tradicionais que, com seus costumes, rituais, sua organização econômica e social em castas e estamentos rígidos, pré-fixava os destinos individuais e a mobilidade dos indivíduos nas sociedades pré-modernas. Por outro lado, este mesmo fenômeno produziu, em compensação, "um caráter objetivado incomensurável aos conteúdos práticos da vida" (Simmel, 2005c, p. 23), isto é, uma expansão dos produtos humanos inassimilável à individualidade e uma redução dos valores a um único valor - o monetário. A esse respeito, sustenta Simmel: "o cálculo necessariamente contínuo do valor em dinheiro faz com que este apareça, finalmente, como o único valor" (Idem, 2005c, p. 31).

O dinheiro, o "equivalente para tudo e para todos", é, de acordo com Simmel, o agente fundamental desta "grande transformação" na relação entre personalidade e comunidade, entre indivíduo e os produtos do seu trabalho, entre os indivíduos e suas formas de associação, no que se 
refere a uma crescente intensificação da abstração na vida social. Quanto mais o dinheiro e a economia se tornam fundamentais para a vida das sociedades modernas, mais as funções abstratas e intelectuais sobrepujam as particularidades subjetivas dos indivíduos.

Não por acaso, o sociólogo e filósofo berlinense afirma que o "dinheiro é o Deus da época moderna" (Simmel, 2005c, p. 36). Sua interpretação sociológica do dinheiro exprime a operação de uma visão trágica como perspectiva explicativa e avaliativa do mundo moderno. No dinheiro, vige uma espécie de autocontradição fundamental, trágica, pois ele confere, por um lado, um caráter impessoal, anteriormente desconhecido, a toda atividade econômica, e, por outro, aumenta, proporcionalmente, a autonomia e a independência da pessoa (Simmel, 2005c).

O desmantelamento das relações de dependência pessoal e a liberdade de usufruir individualmente dos objetos de desejo, frutos do trabalho humano, provocados pelo dinheiro, chocam-se, por conseguinte, com novos constrangimentos oriundos da expansão e institucionalização da economia monetária.

Em Filosofia do Dinheiro, Simmel explora as contradições inerentes produzidas pela institucionalização da economia monetária para os indivíduos modernos, isto é, entre o dinheiro e a "vida interior do sujeito". No mundo moderno, destaca Simmel, o dinheiro é um elemento praticamente onipresente nas interações sociais, e , por suas características e determinações, transforma radicalmente a vida social e subjetiva dos indivíduos. De um mecanismo de mediação de transações econômicas, o dinheiro constitui, na vida moderna, uma força determinante nas formas de sociabilidade e na estrutura das relações sociais dos indivíduos. O poder mágico e unificador do dinheiro na modernidade pode ser observado em dois aspectos centrais da sociabilidade moderna: primeiro, como representação abstrata do valor, o dinheiro tornase capaz de submeter e referir o valor de todos os objetos a si mesmo, isto é, o preço, a circulação de mercadorias, as reservas; segundo, o dinheiro se entrelaça em um vastíssimo espectro de relações sociais convertendo 
as trocas monetárias em uma das principais e mais recorrentes formas de interação (Simmel, 1977).

Na economia monetária, o valor de um objeto não é definido pela individualidade do sujeito, seu desejo e apreciação subjetiva, mas pelas determinações recíprocas dos próprios objetos conforme a dinâmica da esfera das trocas econômicas. O valor de todos os objetos, na modernidade, é subjugado pelo dinheiro. Determinação e valor, como sustenta Simmel, supõem, para a eficácia das trocas e dos valores do objeto, o sacrifício por parte do indivíduo de sua capacidade interna de significar, enquanto força determinante de sua relação com o objeto. A esse respeito, conclui Simmel: "O decisivo na relação com a objetividade do valor econômico, que delimita a esfera econômica como esfera autônoma, consiste no fato de sua validez transcender, em princípio, o sujeito individual" (Simmel, 1977, p. 48).

Dito de outro modo, para que o dinheiro seja concretamente o meio de troca absoluto, o equivalente universal de todas as qualidades, $\mathrm{o}$ indivíduo deve renunciar a sua aptidão subjetiva de dar sentido às coisas, ou seja, de sua autonomia e diferença qualitativa em relação ao objeto e, assim, "aceitar o valor" que a esfera econômica define para ele. Se, por um lado, o dinheiro representa a possibilidade da realização de todos os anseios e desejos que o dinheiro pode comprar (autorrealização individual), isso só é possível submetendo-se a uma esfera impessoal e abstrata e ao seu arbítrio na definição dos valores numéricos, como condição de acesso aos bens desejados. Por isso, a economia monetária é a dominação por excelência da impessoalidade sobre o singular e o autêntico.

Com a consolidação do dinheiro como meio de troca e equivalente geral de todos os valores, a individualidade teve de enfrentar uma equivalência quantitativa de todas as qualidades dos objetos e a autonomia crescente do mundo dos objetos, cada vez mais libertos e distantes dos homens. Ou seja, a despeito do individualismo subjetivo moderno e da abundância dos produtos dispostos à escolha individual, os objetos e as relações desindividualizam-se pela quantidade - traduzidos em valores monetários e abstratos - e a distância subjetiva entre o ser humano e as coisas que ele produz cresce mais e mais na 
cultura. Em outras palavras, o mundo moderno experimenta o atrofiamento da capacidade de significação e apropriação significativa dos objetos produzidos e consumidos pelos indivíduos. Podemos observar, com efeito, nessa análise de Simmel, como o dualismo sujeito-objeto tem, no fenômeno do dinheiro, sua expressão por excelência no pensamento simmeliano.

A autocontradição fundamental do dinheiro consiste em seu impacto ambivalente na constituição da liberdade e objetivação modernas. Os efeitos da economia monetária sobre a individualidade são ambíguos. $\mathrm{Na}$ mesma medida em que o dinheiro propicia uma libertação para a afirmação individual, - "com o dinheiro na bolsa, estamos livres..." (Simmel, 1977, p. 30) - expandindo as possibilidades de desenvolvimento, vontade e associação da individualidade, ele a aprisiona em relações sociais e atividades objetivadas e reificadas que dispensam a totalidade subjetiva da pessoa. A subjetividade liberada pelo dinheiro torna-se, progressivamente, uma subjetividade fragmentada e tolhida pelas relações monetárias. $\mathrm{O}$ dinheiro, na cultura e nas relações sociais modernas, significa, a um só tempo, liberdade e novos constrangimentos.

Como uma síntese de liberdades e novos constrangimentos, o dinheiro alça a individualidade como um problema, uma dialética de tensão permanente e não resolvida. A liberdade da individualidade advinda da economia monetária é trágica, na medida em que ela carrega e implica coações e formas que, novamente, a limitam, a tolhem e a alienam de suas produções e possibilidades.

$\mathrm{Na}$ análise simmeliana dos efeitos da divisão do trabalho sobre a cultura e a relação do indivíduo com os produtos de sua subjetividade, podemos encontrar este mesmo problema da autocontradição fincada na individualidade. Para Simmel, existe um descompasso entre os feitos extraordinários da especialização da divisão do trabalho no âmbito da produção dos artefatos da vida em sociedade, por um lado, e os conteúdos significativos da existência e das capacidades expressivas individuais. Dito de outro modo, o desenvolvimento da cultura objetiva, produzida pela ação organizada e especializada do homem moderno, não é acompanhado 
por um desenvolvimento similar quanto à sensibilidade humana, isto é, da cultura subjetiva dos indivíduos.

A divisão social do trabalho proporcionou, certamente, uma produção sem paralelo de bens e serviços que envolvem e preenchem objetivamente nossa vida, mas, como observa Simmel, “(...) a cultura dos indivíduos, pelo menos nas classes altas, de maneira alguma progrediu, em muitos casos até regrediu" (Simmel, 2005a, p. 44). As coisas produzidas e o próprio processo de produção foram alçados a um estatuto significativo tal, na modernidade, que parece sobrepujar os próprios produtores.

Tal como no caso do dinheiro, a divisão do trabalho e o avanço da técnica são caracterizados por uma autocontradição essencial, geradora da discrepância entre a cultura tornada objetiva e a subjetiva. A capacidade e os produtos da exteriorização humana e a capacidade individual e subjetiva de dotar tais produtos de sentido, apropriando-se significativamente deles, não coincidem; muito pelo contrário, enquanto uma é hipertrofiada a outra cada vez mais se acanha diante do volume e velocidade do mundo das coisas. Para o sociólogo berlinense, o modo pelo qual os indivíduos se relacionam e assimilam os objetos é fundamental para definir sociologicamente a natureza peculiar do universo social em questão e o estatuto subjetivo da individualidade nessa forma de sociedade. A relação com a objetividade é, portanto, socialmente constituinte da individualidade, das formas de associação e das interações sociais (Simmel, 2006).

Na divisão social do trabalho, o incremento do poder da criatividade humana não corresponde nem gera, por conseguinte, o incremento semelhante da capacidade individual de assimilar os objetos, isto é, os produtos do espírito objetivo, decorrentes da expansão e eficiência da engenhosidade humana pela divisão do trabalho. Enquanto o acervo da cultura objetiva cresce diariamente, alargando-se para as mais variadas esferas e dimensões da vida social e individual, a cultura subjetiva, o "espírito individual somente pode estender as formas e conteúdos de sua constituição em uma aceleração contida, seguindo apenas de longe a cultura objetiva" (Simmel, 2005a, p. 45). 
Nesse sentido, o termo "tragédia da cultura", cunhado por Simmel para intitular este descompasso entre intensificação da objetivação da cultura e atrofiamento da capacidade de apropriação/relacionamento significativo da subjetividade humana, não é uma simples coincidência (Simmel, 2005b).

Este impulso trágico da cultura moderna atravessa as próprias estruturas mentais dos indivíduos modernos ao acirrar neles o sentimento de que as criações e as construções humanas, que se sofisticam e se renovam cada vez mais, não coincidem, em última instância, enquanto frutos da sua criatividade, cooperação e energias subjetivas, mas como coisas independentes, que se autonomizaram e em face das quais eles não podem nem conseguem se reconhecer. $\mathrm{O}$ mundo das coisas e dos objetos possuem uma lógica própria de desenvolvimento, desprendida da direção na qual poderiam se afeiçoar ao desenvolvimento subjetivo da alma humana. A cultura objetiva parece ser, com efeito, superior em termos de qualidades e potencialidades ao mundo do espírito. Este é o mal-estar da moderna vida do espírito, sobrepujada por aquilo mesmo que os indivíduos criaram para libertá-la e desenvolvê-la.

A autocontradição trágica da época moderna é exatamente esse mal-estar, produzido por um desenvolvimento histórico-cultural simultâneo das condições para uma individualidade mais diferenciada e de formas socioculturais que se tornam objetivadas e passam a andar sobre os seus próprios pés como se tivessem vida própria. Eis aí nossa condição trágica, conforme Simmel, uma situação cultural de profunda fragilidade subjetiva, em que o homem moderno, diante de um mundo objetivo cada vez mais avassalador, veloz e autônomo, envolvido de produtos culturais variados, frutos de seu engenho e esforço técnico-cultural, aos quais, contudo, ele não pode assimilar significativamente em seu conjunto ou individualmente (Simmel, 2005b).

Os processos sociais e históricos que produziram as pré-condições para uma individualidade mais diferenciada comprometem por forças internas a eles mesmos a individualidade tornada possível. O dinheiro, a divisão do trabalho e a urbanização são produtos das forças que provêm da 
capacidade de criar dos próprios indivíduos, mas que, contudo, voltam-se contra eles mesmos e seus anseios.

Portanto, a sociologia da modernidade de Simmel pode ser definida como uma sociologia das autocontradições da cultura moderna. O seu ponto de vista trágico sobre a vida e as formas sociais humanas radica exatamente no fato de não apartar destas últimas, de seu curso e desdobramentos lógicos, as oposições autocontraditórias e patologias que Ihes são, a um só tempo, constituintes, inerentes e incontornáveis.

\section{Weber: o trágico como paradoxo das ações}

Talvez Max Weber seja, entre os clássicos da sociologia, o mais trágico. Buscou enfrentar, com lucidez e paixão, os antagonismos modernos em todo o seu ímpeto e plenitude trágicos. Karl Jaspers, em uma carta no final de sua vida, o definiu como alguém que "enfrentou as realidades sem restrições, da mesma maneira intransigente que Kierkegaard e Nietzsche; não como aqueles adolescentes eternos, mas como um homem que permitiu que fosse despedaçado" (Jaspers apud Radkau, 2009, p. 559).

Não é gratuito que, em uma de suas biografias, cujo título é Max Weber: a política e o espírito da tragédia, seu biógrafo escreva a seu respeito: "Ele se preocupou com os indivíduos enquanto pessoas em busca de sentidos e com a história como um drama de propósitos e destinos, visto por uma lente obscura" (Diggins, 1999, p. 89).

A preocupação metodológica weberiana de dar conta tanto dos sentidos e das motivações dos agentes sociais quanto das regularidades causais que caracterizam a singularidade histórico-cultural de fenômenos sociais, ou seja, a tensão entre sentido e regularidade causal, exprime que até sua epistemologia é animada por um ar trágico.

Em diversos aspectos da interpretação weberiana acerca do desenvolvimento histórico-cultural da modernidade ocidental, podemos apreender um ponto de vista trágico de abordagem. No campo das atitudes éticas, Weber também cultiva uma visão trágica. Em um mundo desprovido de fundamentos últimos, sublimes 
e transcendentes, a cultura moderna exige uma aceitação trágica e resignação heroica dessa verdade dura e desencantada (Cohn, 1979). No confronto entre ética da responsabilidade e ética da convicção, em que cada qual "tem de decidir qual é para ele o Deus e o qual o demônio que orienta e controla os cordões da sua vida", vislumbramos o quanto Weber abraça para si o espírito trágico, enquanto uma atitude intelectual e ética na compreensão e enfrentamento dos dilemas do mundo moderno (Weber, 1984, p. 175; 183).

Os paradoxos éticos da responsabilidade e da convicção, que pesam e lutam dentro do peito do homem moderno, são uma perfeita tradução do trágico transposta dos palcos gregos para dentro da vida cotidiana moderna. Influenciada pelas diferentes e autônomas ordens da vida em que as condutas e posicionamentos valorativos humanos encontram sua conflitante orientação, o viver moderno é, assim, profundamente trágico, pois, "o trágico traduz uma consciência dilacerada, o sentimento das contradições que dividem o homem contra si mesmo" (Vernant; VidalNaquet, 1999, p. 02).

Como podemos perceber, a obra de Weber dispõe de diversas entradas para examinar sua sensibilidade trágica no trato analítico e éticopolítico da realidade social. De fato, poder-se-ia afirmar que o processo de racionalização nos estudos de Weber é marcado por um entendimento trágico, na medida em que esses estudos ressaltam as tensões internas e os desdobramentos históricos e culturais paradoxais produzidos. Tomemos, por exemplo, sua análise da ciência moderna.

Ao contrário de outras atividades da esfera da cultura, o trabalho científico está preso ao curso do progresso, assinala Weber. As realizações científicas, em razão da lógica e leis da própria ciência, enquanto uma esfera social que se autonomiza, estão fadadas à superação sistemática, de modo que, na ciência, "não podemos trabalhar sem a esperança de outros avançarem mais do que nós" (Weber, 1982, p. 164).

Contudo, não é no sentido ambíguo do trabalho científico como vocação para o cientista que o trágico e o paradoxal da ciência se revelam em todo o seu brilho na análise weberiana. Vejamos. 
Para Weber, a ciência moderna é parte de um processo geral mais amplo. Ela é uma fração do processo milenar de intelectualização da cultura ocidental, o qual, mediante racionalizações sistemáticas e pela técnica, desencanta progressivamente o mundo de forças mágicas e misteriosas incalculáveis, convertendo-as em fenômenos passíveis de explicação e domínio pelo cálculo humano. A ciência, como técnica de domínio da vida, sustenta-se na crença desencantada de que os fenômenos do mundo podem ser conhecidos e controlados. Nesse sentido, a ciência no decorrer do seu desenvolvimento histórico, da Grécia Antiga à Renascença, nutriu, sem sucesso, ilusões que foram desaparecendo até o seu culminar no mundo moderno; "a ciência como caminho da verdade eterna, como caminho para Deus" e para a "verdadeira felicidade" mostrou-se como tão somente ilusões confortadoras num mundo desencantado (Weber, 1982, p. 167-9).

Esvaziada de uma finalidade última, restou à ciência tão somente a realização do progresso e do domínio da vida por intermédio do cálculo e da técnica. Ora, Weber assinalará justamente que a ciência, ainda que possa servir como meio de orientação e expectativa para a vida e a conduta individual, não responde quanto ao que devemos fazer e como devemos viver. Seu propósito de constituir uma técnica de domínio da vida não é capaz de justificar a si mesmo, isto é, cientificamente, como uma ética prática superior às demais a ser seguida na esfera pessoal. Como afirmará Weber: "a defesa científica é destituída de sentido em princípio porque as várias esferas de valor do mundo estão em conflito inconciliável entre si" (Weber, 1982, p. 174).

Mais ainda, todo o conhecimento que ela produziu sobre a realidade não significou um maior conhecimento do homem moderno acerca das condições em que vive. Muito pelo contrário, o homem moderno vive circundado de objetos técnicos e sistemas que ele desconhece profundamente (Weber, 1982). O esclarecimento científico produziu, também, estranhamento e o mundo opaco de coisas.

Finalmente, a crença da ciência na libertação do ser humano dos poderes mágicos, em função da utilização dos meios racionais, metódicos 
e técnicos, preparou o caminho da dominação racional-legal moderna e seus complexos institucionais peculiares, o Estado burocrático e a economia capitalista. Os meios técnicos da ciência e sua atitude metódica e calculada diante do mundo ajudaram a engendrar novas estruturas de dominação que assumiram as formas objetivadas da empresa capitalista, do Estado moderno, do direito, da burocracia e da administração, as quais tentam encerrar as condutas humanas num universo previsível e disciplinado, sem referência explícita aos conteúdos éticos substantivos, exceto a de um racionalismo prático e de dominação do mundo (Weber, 1994, p. 141-2).

O problema da ação e suas consequências não intencionais, tema clássico da sociologia weberiana, constitui, certamente, uma das entradas mais profícuas para abordar o ponto de vista trágico de seu pensamento social. O elemento trágico da existência humana pode ser apreendido no peculiar e sofisticado tratamento que Weber dispensa à ação social ${ }^{5}$, entendida como dotada de sentido e subjetivamente visada: "a premissa transcendental de qualquer ciência da cultura reside na circunstância de sermos homens de cultura, dotados da capacidade e da vontade de assumirmos uma posição consciente em face do mundo e de lhe conferirmos um sentido" (Weber, 1993, p. 131).

De minha parte, abordarei o trágico no pensamento weberiano em função do papel das consequências não intencionais e imprevistas da ação, no curso de uma experiência histórica. Por isso, sua obra mais conhecida será de vital importância para nossa análise.

O tema, ou problema, da ação não constitui apenas uma das mais fundamentais e recorrentes preocupações da sociologia, sobretudo a

\footnotetext{
${ }^{5}$ Nesse argumento, não estou só. Reinarde Freire Nobre (2000), em seu artigo sobre a racionalidade e a tragédia cultural no pensamento de Weber, sustenta a tese, segundo a qual, a perspectiva weberiana da tragicidade da existência está intimamente ligada à abordagem da ação social. Em seu refinado artigo, Reinarde Nobre prioriza a dimensão metodológica e analítica do racionalismo em Weber, isto é, os princípios racionalistas da análise weberiana e o tema das racionalizações da vida moderna, os quais, de acordo com o autor, explicitam aos indivíduos modernos o paroxismo da racionalidade e do desencantamento do mundo na modernidade.
} 
weberiana. Na Poética de Aristóteles, em sua análise sobre a tragédia, afirma o filósofo: "os homens possuem tal ou tal qualidade conformemente ao caráter, mas são bem ou mal-aventurados pelas ações que praticam (Aristóteles, 1987, p. 206). O problema das consequências da ação já está colocado nas diversas peças trágicas. Nelas, a questão da relação do ser humano com suas ações, e com as consequências que extrapolam sua consciência e vontade, constitui um dos seus principais motes.

Encontro preocupação muito similar na sociologia compreensiva weberiana. Pode-se dizer, aliás, que elucidar a relação entre as intenções dos agentes e o sentido histórico de suas ações é um dos principais temas de sua empresa investigativa. Para Weber, o mundo é moldado por nossas intenções, mas não da forma como esperávamos originalmente. Toda ação possui efeitos imprevistos que ultrapassam a capacidade de cálculo do sujeito e o escopo de seus propósitos.

Nesse sentido, o seu trabalho mais conhecido, A Ética Protestante e o Espírito do Capitalismo, é bastante elucidativo a propósito da relação entre ações e consequências. Nele, temos uma investigação perspicaz acerca de alguns dos principais ingredientes históricos relativos ao amplo processo de transformação sociocultural que formou, em larga medida, as principais características dos nossos modos de ser, agir e pensar. A perspicácia de Weber está na tentativa de elaborar uma explicação com respeito à conexão de sentido entre as concepções religiosas do protestantismo ascético (plano das motivações) e a gênese de alguns dos elementos constitutivos decisivos do capitalismo moderno e sua cultura (plano das consequências históricas não premeditadas).

Esse ensaio clássico apresenta, decisivamente, uma apreensão trágica acerca da emergência do capitalismo e do papel do protestantismo ascético. As questões de emergência do ethos da empresa racional burguesa de acumulação e orientação para o lucro, da organização racional do trabalho, da profissão como dever e como dedicação de si são procuradas num âmbito, à primeira vista, inesperado, como é de praxe numa perspectiva trágica, isto é, das éticas religiosas ascéticas do protestantismo (Weber, 2004). 
A ambição explicativa de Weber, nessa obra, consiste em compreender o capitalismo moderno como uma individualidade histórica, isto é, investigá-lo em suas condições históricas de emergência no ocidente sob as características muito singulares que o definem, sobretudo, no tocante à organização racional da atividade produtiva. O sociólogo alemão, então, partirá da hipótese da existência de uma afinidade eletiva, quer dizer, uma correlação não necessária e não premeditada entre a ética protestante, os preceitos éticos e os modos de agir e pensar de algumas seitas protestantes e a formação da empresa capitalista moderna.

Para Weber, o protestantismo ascético se distinguia de outras confissões religiosas em virtude de um ethos racional de condução da vida cotidiana, sustentado em ideais, máximas e preceitos doutrinários como vocação e disposição intensa para o agir no mundo, valorização do tempo produtivo, parcimônia, planejamento prospectivo, a correspondência entre fé e obras, predestinação, entre outros. Dito de outro modo, Weber sustenta que as disposições produzidas pelas exigências e motivações religiosas protestantes moldaram e impulsionaram, de modo não calculado e imprevisto, elementos fundamentais da cultura do capitalismo moderno, sua ética do trabalho e sua forma de organização racional da produção e da acumulação (Weber, 2004).

Não se trata de argumentar que a Reforma produziu o capitalismo ou foi o responsável por sua justificação ideológica e mascaradora. Weber é bastante claro e direto a esse respeito. Os fiéis protestantes, e menos ainda Lutero ou Calvino, não tinham a intenção de modificar as condutas e instituições econômicas e remover os entraves - colocados pelo tradicionalismo - que pesavam sobre estas. A intenção dos reformadores e seus adeptos era clara e convictamente religiosa: buscar a salvação e o testemunho da graça divina neste mundo, mas de olho no outro mundo (Weber, 2004 p. 74; 81).

Por isso, sentencia Weber:

(...) temos que admitir que os efeitos culturais da Reforma foram em boa parte talvez até principalmente, para os nossos específicos pontos de vista - consequências imprevistas e mesmo indesejadas do trabalho dos reformadores, o mais das vezes 
bem longe, ou mesmo o contrário, de tudo o que eles próprios tinham em mente (Weber, 2004, p. 81).

O que Weber afirma, na verdade, é que, a partir da doutrina e da prática do protestantismo ascético, ocorreu uma mudança fundamental na atitude prática e ética em relação ao mundo dos negócios e do trabalho. Desse modo, ao invés de um produto consciente ou um resultado lógicocausal de intenções e ações encadeadas, o "espírito do capitalismo", o fundamento ético de conduta e comportamento no qual se apoia sua significação cultural, é melhor compreendido enquanto o efeito não previsto e não proposital das ideias, disposições produzidas e dos comportamentos puritanos da ascese cristã.

No entanto, o ponto de vista trágico em Weber e que anima seu clássico ensaio não se encerra no jogo aleatório das ações, que faz das intenções e motivações dos homens um "joguete do destino". Este é apenas o primeiro plano do enredo weberiano.

O segundo plano consiste no conteúdo das consequências, por assim dizer. Isto é, naquilo que ações dos agentes produziram a despeito de suas intenções e motivos. Na medida em que o "espírito do capitalismo" se livra dos apoios metafísicos do protestantismo, e passa a sustentar-se e a mover-se sobre os seus próprios pés, de forma secular e mecanizada, os motivos, atitudes e concepções ético-religiosas dos ascetas reformados, que acalentavam suas vidas e conferiam sua dignidade, convertem-se na "crosta de aço" sobre os indivíduos modernos. Com amargor e ironia, afiança Weber: "quis o destino, porém, que o manto virasse uma rija crosta de aço" (Weber, 2004, p. 165).

O capitalismo moderno impõe aos indivíduos, empresários e operários, normas de ação econômica que, se não observadas corretamente, podem implicar a sua desventura e desgraça. A ordem econômica capitalista é para o indivíduo que já nasce em seu interior “(...) como um fato, uma crosta que ele não pode alterar e dentro da qual tem que viver" (Weber, 2004, p. 47-8). 
O manto ascético que envolvia os ideais morais e as ações dos protestantes foi transvalorado pelo capitalismo moderno. E, com isso, um novo cosmos significativo se institucionaliza, suplantando os fundamentos espirituais sublimes da ação e do viver, antes religiosos, morais e éticos, e, agora, econômicos, técnicos, mecânicos e racionais. Assim, a busca pela afirmação da glória de Deus e a confiança na providência dão lugar ao cálculo e à utilidade das ações; a devoção convicta aos princípios éticos e mandamentos divinos, à eficiência econômica; e a satisfação orgulhosa do servir a Deus, ao prazer da satisfação e maximização dos interesses econômicos, à servidão e culto ao dinheiro e à ambição quase esportiva do lucro.

Embora, como destaca Weber, existam afinidades entre a ascese intramundana protestante e o "espírito do capitalismo", isto é, o dever profissional sobre a ação econômica, tal não deixa de ser uma transformação surpreendente. Uma ética religiosa (racionalidade valorativa) animada por valores sublimes e transcendentes, que enchiam de significado e calor moral os seus adeptos, transforma-se em uma doutrina utilitarista fria (racionalidade instrumental). Se estes novos fundamentos do agir humano na sociedade capitalista, por um lado, são capazes de servir como orientação pragmática-utilitária sobre como conduzir a vida, por outro, quando se trata de responder acerca do sentido último desta, eles emudecem, precipitando nos indivíduos modernos um vasto sentimento de vazio e perda de sentido. Eis, então, todo o apelo trágico do entendimento weberiano acerca da emergência do capitalismo moderno.

As últimas páginas do seu clássico ensaio são ainda mais diretas nesse ponto. De modo imprevisto e indesejado, a ética protestante contribuiu, significativamente, para precipitar uma ética do trabalho que agrilhoou a cultura moderna nesta pesada crosta de aço; quer dizer, num tipo de vida em que o ser humano existe tão somente para seu trabalho ou negócio, para o dinheiro e o lucro, quando, na verdade, deveria ser o contrário conforme os propósitos originários do asceticismo protestante.

A gênese do espírito do capitalismo moderno, tal como narrada por Weber em seu ensaio, é uma lição trágica sobre as relações humanas. 
Afinal, o que nos ensinam as tragédias senão as artimanhas, as ironias e a indiferença do destino, das forças e poderes mundanos e extramundanos em relação aos nossos propósitos e motivações?

Como as tragédias, as relações entre o ser humano, a ação e o mundo formam parte da questão primordial contra a qual Weber jamais deixou de se confrontar para atingir suas teses, posicionamentos éticos e generalizações teóricas. As palavras abaixo, escritas por estudiosos franceses com respeito às tragédias gregas, bem poderiam ter saído da lavra de Weber a propósito de seu próprio pensamento sociológico:

A ação humana é, pois, uma espécie de desafio ao futuro, ao destino e a si mesma, finalmente um desafio aos deuses que ao que se espera, estarão ao seu lado. Neste jogo, do qual não é senhor, o homem sempre corre o risco de cair na armadilha de suas próprias decisões. Para ele, os deuses são incompreensíveis (Vernant; VidalNaquet, 1999, p. 21).

\section{Considerações finais}

Tentei aqui discutir, sem exaustividade, como o trágico, entendido como uma singular concepção do curso do mundo e do lugar do ser humano em face deste, apresenta-se nas construções teóricas e na interpretação do desenvolvimento histórico da modernidade de Simmel e Weber. Ambos os sociólogos são autores preocupados e interessados nos problemas existenciais e civilizatórios que a vida no mundo moderno impõe para os indivíduos. Discuti aqui alguns temas, conceitos e reflexões que testemunham esse interesse e, sobretudo, a sensibilidade trágica que afeiçoa suas perspectivas.

No primeiro, analista refinado e sutil das ambivalências modernas, identifiquei o seu "ponto de vista trágico" como pressuposição de uma autocontradição fundamental ou efeitos ambivalentes que habitam os processos e fenômenos da vida e da história. A modernidade como um estilo de vida ambivalente, produzido por antinomias e dualismos fundamentais entre sujeito e objeto, cujo engendramento deriva de um mesmo processo ou fato - o dinheiro ou a divisão do trabalho. No segundo, esforcei-me 
em exprimir como o trágico emerge, de maneira surpreendente, irônica e indesejada, como vindo de alhures, das consequências não previstas e não intencionais da ação dos agentes. Weber como um intérprete sofisticado dos paradoxos que moldaram a cultura moderna.

As visões simmeliana e weberiana da condição trágica da modernidade estão bastante próximas, sobretudo neste sentido: a condição trágica do mundo moderno não é pensada como uma fatalidade que acomete heróis excepcionais, "joguetes do destino", mas enquanto uma condição que atinge a cotidianidade da vida sociocultural moderna e da pessoa comum. Ambos, sob princípios e abordagens diferentes, concordam em que a estrutura - ou o significado - do processo cultural moderno é uma estrutura trágica, de autocontradições e paradoxos que expõem profunda fratura de uma época. Se, por um lado, os processos racionalizadores da cultura moderna estão na origem de importantes ganhos civilizatórios na liberdade e desenvolvimento das potencialidades humanas, por outro, é também verdade que esses mesmos processos originaram novos constrangimentos e coações que petrificam a subjetividade libertada. Ou seja, os processos históricos que libertaram os homens dos antigos grilhões da tradição os dominaram sobre coerções e sujeições novas.

É nesse desiderato de crescentes e cada vez mais insolúveis oposições e paradoxos civilizatórios que o trágico da época moderna se desvela. As supostas forças emancipadoras e as pretensões dos indivíduos à vida livre e plena revelam-se, na verdade, e em seu próprio devir, como forças de dominação e aprisionamento dos indivíduos. A definição de Szondi sobre o trágico cai, então, sob medida, pois "é trágico apenas o declínio que ocorre a partir da unidade dos opostos, a partir da peripécia de algo em seu contrário, a partir da autocisão" (Szondi, 2004, p. 84-5).

O trágico, nas sociologias de Simmel e Weber, consiste nessa dialética de tensão, imprevista e irresolúvel, entre liberdade e dominação em um desenvolvimento histórico particular. Dito de outro modo, cultura e história possuem um caráter trágico para os autores mencionados. É nas tramas da cultura e da história que se desenlaçam os destinos dos indivíduos e 
das sociedades, isto é, o jogo complexo entre as ações dos indivíduos e os seus produtos.

Nesse sentido, poder-se-ia afirmar, com segurança, que a sensibilidade trágica, nesses autores, combate a postura intelectual e política que abraça com otimismo a modernidade e suas promessas de progresso e de liberdade individual e igualdade. Contudo, isso não significa advogar em favor de uma visão melancólica e de completa rejeição da nova ordem social. A crítica do mundo moderno, em Simmel e Weber, deve muito à sensibilidade trágica que lhes talhou, de modo peculiar e humanista, o olhar sobre a história da formação da cultura moderna.

O ponto de vista trágico constitui, em ambos, uma fonte de imaginação conceitual acerca dos elementos em conflito que configuram a singularidade da cultura moderna em relação às configurações civilizatórias anteriores. $\mathrm{O}$ trágico, com efeito, não é uma figura de linguagem, uma estratégia retórica ou estilística, mas uma sensibilidade intelectual que abre uma perspectiva teórico-filosófica sobre o devir do mundo, suas fraturas e suas tendências e consequências na vida sociocultural.

Evidentemente, autores densos e complexos e com obras vastas e dispersas como Simmel e Weber, permitem, decerto, outras chaves e entradas para explorar a questão do trágico e de como este se revela em suas sociologias. Por isso, é certo, há pontos que podem - e devem - ser aprofundados e, mesmo, revistos com mais acuidade e vagar. Contudo, nossa intenção e esforço consistiram em abrir e explorar caminhos e pistas dentro dessa temática metateórica em sociologia. Analisar as sociologias de Simmel e Weber à luz de suas conexões com outras fontes expressivas do pensamento humano significa explorar "estruturas profundas" e "dimensões inarticuladas" do pensamento sociológico.

Sem maiores ambições, tentei reforçar, ainda que tímida e indiretamente, a ideia de que as Artes e a cultura geral, enquanto forma e campo de pensamento e experiência, podem constituir uma fonte fecunda e original, capaz de nutrir significativamente o pensamento científico, em especial as ciências do espírito e da cultura, e assim, reanimar uma ideia 
poderosa e atraente da interpretação de Robert Nisbet (2000) sobre os clássicos da sociologia.

Diante da inegável presença e força da intuição e da sensibilidade artísticas nas elaborações fundadoras da ciência da sociedade, Nisbet concebia a sociologia como uma forma de arte. Sem negar seu pertencimento à tradição científica ou separá-la dos modos de pensar da ciência, defendia que a sociologia dos clássicos opera a partir de uma imaginação criativa similar àquela talhada pelos artistas em seu confronto com o mundo, a qual, diga-se, não é, em absoluto, avessa ou refratária aos esquemas cognitivos do investigador científico. A meu ver, as obras e as sociologias de Simmel e Weber são exemplos vivos e ricos dessa ideia.

Alyson Thiago Fernandes Freire é docente de Sociologia do Instituto Federal de Educação, Ciência e Tecnologia do Rio Grande do Norte (IFRN) e pesquisador do Núcleo de Estudos Críticos em Subjetividades e Direitos Humanos (NUECS-DH).

Đalyson_thiago@yahoo.com.br

\section{Referências}

1. ALEXANDER, Jeffrey C. O novo movimento teórico. Revista Brasileira de Ciências Sociais, v. 2, n. 4, p. 5-28, jun. 1987.

2. ARISTÓTELES. Poética. Trad. Eudoro de Souza. São Paulo: Nova Cultura, 1987.

3. ARON, Raymond. As etapas do pensamento sociológico. Martins Fontes: São Paulo, 2008.

4. BILLINGS, Joshua. Genealogy of the Tragic: Greek Tragedy and German Philosophy. Princeton: Princeton University Press, 2014.

5. COHN, Gabriel. Crítica e resignação: fundamentos da sociologia de Max Weber. São Paulo. Queiroz, 1979.

6. DIAS DUARTE, Luiz Fernando. A pulsão romântica e as ciências humanas no ocidente. Revista Brasileira de Ciências Sociais, junho, v. 19, n. 55, p. 5-18, 2004.

7. DIGGINS, John Patrick. Max Weber: a política e o espírito da tragédia. Rio de Janeiro: Record, 1999. 
8. FRISBY, David. The Ambiguity of Modernity: Georg Simmel and Max Weber. In: MOMMSEN, Wolfgang; OSTERHAMMEL, Jurgen (org). Max Weber and his Contemporaries. London. Routledge, German Historical Institute, 2006.

9. GOULDNER, Alvin. Romanticism and Classicism: Deep Structures in Social Science. In: GOULDNER, Alvin. For Sociology: Renewal and Critique in Sociology Today. Nova York: Basic Books, 1973. p. 464-5.

10. HÖLDERLIN, Friedrich. Reflexões. Trad. Márcia de Sá Cavalcante e Antonio Abranches. Rio de Janeiro. Relume-Dumará, 1994.

11. LEPENIES, Wolf. As três culturas. São Paulo: Ed. da USP, 1996.

12. LESKY, Albin. A tragédia grega. Trad. J. Guinsburg et al. 3. ed. São Paulo: Perspectiva, 2006.

13. MACHADO, Roberto. O nascimento do trágico: de Schiller a Nietzsche. Rio de Janeiro: Zahar, 2006.

14. NIETZSCHE, Friedrich. A origem da tragédia. 12 ed. Lisboa: Raiz Editora, 2006

15. NISBET, Robert. La formación del pensamiento sociológico. Buenos Aires. Amorrortu Editores, 1969.

16. NISBET, Robert. A sociologia como forma de arte. Revista Plural - Faculdade de Sociologia da USP. São Paulo, p. 111-30. 1ํo sem. 2000.

17. NOBRE, Renarde Freire. Racionalidade e tragédia cultural no pensamento de Max Weber. Tempo Social, v. 12, n. 2, 2000.

18. RADKAU, Joachim. Max Weber: a Biography. Cambridge: Polity Press, 2009.

19. SEIDMAN, Steven. Liberalism and the Origins of European Social Theory, Oxford: Basil Blackwell, 1983.

20. SIMMEL, Georg. Filosofia del dinero. Madrid: Instituto de Estudios Políticos, 1977.

21. SIMMEL, Georg. El individuo y la libertad. In: SIMMEL, Georg. Ensayos de crítica de la cultura. Barcelona: Península, 1986.

22. SIMMEL, Georg. La intuición de la vida: cuatro capítulos de metafisica. Buenos Aires: Terramar, 2001.

23. SIMMEL, Georg. A divisão do trabalho como causa da diferenciação. In: SOUZA, Jessé; ÖELZE, Berthold (org). Simmel e a Modernidade. Brasília: Editora da UnB, 2005a.

24. SIMMEL, Georg. O conceito e a tragédia da cultura. In: SOUZA, Jessé; ÖELZE, Berthold (org). Simmel e a modernidade. Brasília: Editora da UnB, 2005b.

25. SIMMEL, Georg. O Dinheiro na Cultura Moderna. In: SOUZA, Jessé; ÖELZE, Berthold (org). Simmel e a modernidade. Brasília: editora da UnB, 2005c. 
26. SIMMEL, Georg. O indivíduo e a sociedade. In: SIMMEL, Georg. Questões fundamentais da sociologia. Rio de Janeiro: Zahar, 2006.

27. SIMMEL, Georg. Schopenhauer e Nietzsche. Rio de Janeiro: Contraponto, 2011.

28. SOLMS-LAUBACH, Franz. Nietzsche and Early German and Austrian Sociology. Nova York: WdG, 2007.

29. SOUZA, Jessé; ÖELZE, Berthold (Orgs). Simmel e a modernidade. Brasília: Editora da UnB, 2005. p. 9-20.

30. SZONDI, Peter. Ensaio sobre o trágico. Rio de Janeiro: Zahar, 2004.

31. TAYLOR, Charles. As Fontes do Self: A construção da identidade moderna. São Paulo: Loyola, 1997.

32. VERNANT, Pierre; VIDAL-NAQUET, Pierre. Mito e tragédia na Grécia Antiga I e II. São Paulo: Perspectiva, 1999.

33. WEBER, Max. A ciência como vocação. In: WEBER, Max. Ensaios de sociologia. 5 ed. Rio de Janeiro: Guanabara, 1982, p. 154-83.

34. WEBER, Max. Metodologia das ciências sociais. v. I. São Paulo: Cortez, 1993.

35. WEBER, Max. Economia e sociedade. v. I. Brasília: Editora da UnB, 1994.

36. WEBER, Max. A ética protestante e o espírito do capitalismo. São Paulo: Companhia das Letras, 2004.

37. WILLIAMS, Raymond. Tragédia moderna. São Paulo: Cosac \& Naif, 2002.

Recebido: 22.08.2016

Aceito: 19.12.2017 